5 United Kingdom Trial of Early Detection of Breast Cancer Group. Trial of early detection of breast cancer: description of method. $\mathrm{Br} f$ Cancer 1981;44: 618-27.

6 Roberts MM, Alexander FE, Anderson TJ, Chetty U, Donnan PT, Forrest P, et al. Edinburgh trial of screening for breast cancer: mortality at seven years. et al. Edinburgh trial of

7 Lundgren B, Jakobsson S. Single view mammography; a simple and efficien approach to breast cancer screening. Cancer 1976;38:1124-9.
8 Peeters $\mathrm{PH}$, Verbeek AL, Hendriks JH, van Bon MJ. Screening for breas cancer in Nigmegen. Report of 6 screening rounds, 1976-1986. In $\mathcal{F}$ Cancer 1989;43:226-30.

9 Ellman R, Angeli N, Christians A, Moss S, Chamberlain J, Maguire P. Psychiatric morbidity associated with screening for breast cancer. Brf Cancer 1989;60:781-4.

(Accepted 27 November 1991)

\title{
Organ donation from intensive care units in England and Wales: two year confidential audit of deaths in intensive care
}

\author{
Sheila M Gore, Deborah J Cable, Annabel J Holland
}

Abstract

Objectives-Quantify possible increases in cadaveric organ donation from intensive care units; identify major sources of regional variation.

Design-Confidential audit of all deaths in intensive care units in England in 1989 and 1990 and in Wales in 1990.

Setting -15 regional and special health authorities in England; Wales.

Patients - 24023 audited deaths in England; 682 in Wales.

Main outcome measures-Solid organ and corneal donor rates per 100 deaths; solid organ donor rate per 100 confirmed brain stem deaths; regional variation in (a) whether brain stem death was possible diagnosis, (b) general medical contraindications to donation, $(c)$ relatives' refusal.

Results-Confirmed brain stem death accounted for $2389(10 \%)$ audited deaths in England. In 438 $(18 \%)$ there was a general medical contraindication to organ donation, and of $1829(94 \%)$ families asked about donation, 557 (30\%) refused. Data for England suggested that among potential donors the heart is suitable for transplantation in $65 \%$ of cases, the kidneys in $95 \%$, the liver in $71 \%$, the lungs in $31 \%$, and the corneas in $92 \%$. Reasons for any shortfall in achievement of transplantation varied with organ type. Solid organ and corneal donor rates per 100 deaths were 5.0 and 3.9 respectively in England and 4.3 and 2.1 respectively in Wales. The solid organ donor rate per 100 confirmed brain stem deaths was 50 in England and 41 in Wales.

Conclusions - A $20 \%$ increase in number of cadaveric kidney donors from intensive care could be achieved by prompt testing for brain stem death and a quarter reduction in relatives' refusals.

\section{Introduction}

In 1987 the Working Party on the Supply of Donor Organs for Transplantation recommended: "Each Authority should establish an audit in its constituent hospitals in order to record all instances of the diagnosis of brain-stem death, the number of requests made, the number and nature of organ donations and the reasons for any shortfall." As a result the Department of Health initiated a cost efficient, though not comprehensive, centralised, confidential audit of all deaths in intensive care units in England (except those for coronary care only and neonatal intensive care) in 1989 and $1990 .{ }^{23}$ The audit aimed at achieving efficiency, precision of estimation, and reproducibility between years and at gaining insight to regional variation. The audit cost less than $£ 20000$, enjoyed good collaboration in the return and validation of audit forms, and yielded consistent findings in 1989 and 1990 . Wales joined the confidential audit in 1990.

Cohen has called for the deaths of patients ventilated outside designated intensive care units to be audited also. ${ }^{4}$ Collins reported the background to, and Feest et $a$ the preliminary assessment of, an interventional ventilation protocol for identifying and managing patients with terminal cerebrovascular accidents who are potential organ donors but are lost to the transplant programme by being admitted to general medical wards rather than to the intensive care unit. ${ }^{56}$ Gentleman et al audited all deaths, whether on the ward ( 272 deaths) or in the intensive care unit ( 281 deaths), over four years (1986-9) in the Institute of Neurological Sciences, Glasgow. ${ }^{7}$ They noted reservations about interventional ventilation: a reluctance to embark on major intervention with no prospect of helping the patient and unwillingness to commit professional time and intensive care resources in these circumstances. A comprehensive one year regional study of all deaths, including both those in ventilated patients and other deaths outside intensive care units, was undertaken by Salih $e t$ al in 21 acute hospitals in south and west Wales serving a population of $2 \cdot 2$ million. ${ }^{8}$ But the cost was high $(£ 70000)$, because the case notes of all deceased patients were examined by fieldworkers soon after the death, and would have been prohibitively so for England's geographically dispersed and more than 20 times greater population.

\section{Methods}

The audit began on 1 January 1989 in regional and special health authorities in England and on 1 January 1990 in Wales; it ended on 31 December 1990. Books of serially numbered audit forms ${ }^{2}$ were issued by the Department of Health to health authorities for completion in each intensive care unit. Liaison between health authorities, the Department of Health, and the Medical Research Council's biostatistics unit was through designated regional personnel. They were also intermediary between the statistical centre and intensive care units in the return and validation of audit forms, thereby ensuring anonymity of intensive care units. Three audit periods were scheduled in 1989January to March, April to June, July to Decemberand two in 1990. In the first and second audit phases $30 \%$ and $15 \%$ of audit forms respectively failed logical checks and had to be returned to intensive care units for correction. ${ }^{9}$ In later periods fewer than $10 \%$ of audit forms failed initial validation.

\section{Results}

Altogether 12133 and 11890 deaths in intensive care units were audited in England in 1989 and 1990 respectively out of total numbers of 12600 and 13000 (estimated after correcting for period specific noncompliance or partial compliance). Compliance by intensive care units in England was thus $96.3 \%$ in the first year and $91.5 \%$ in the second year. ${ }^{10}$ In Wales, where the audit was introduced in 1990 without a three
Correspondence to:

BMF 1992;304:349-55 
month initiation period, 682 deaths were audited out of an estimated 800 (compliance $85 \cdot 3 \%$ ).

A total of 634 and 568 cadaveric donors of solid organs from intensive care units were audited in England in 1989 and 1990 respectively when the total numbers of such donors reported to the United Kingdom Transplant Service were 763 and 761 . Adjusted for compliance, intensive care units currently account for an estimated $84 \%$ of cadaveric solid organ donors in England, and the proportion in Wales is similar. Hence a confidential audit focused on deaths in intensive care units, although not comprehensive, is highly representative of cadaveric solid organ donation.

\section{AUDITED DEATHS IN ENGLISH UNITS}

Figure 1 shows the flow chart for audited deaths in English intensive care units during 1989 and 1990 . The mean age of the patients at death was 57.4 (SD 21.5) years, and over $14437(60 \%)$ were male. Extracranial causes accounted for $19612(82 \%)$ of the deaths. Doctors completed the audit forms in $59 \%$ of cases in 1989 and $52 \%$ of cases in 1990 .

Of all 24023 deaths that were audited in the two years, in only 3266 cases $(13.6 \%$; $95 \%$ confidence interval $13 \cdot 2 \%$ to $14 \cdot 0 \%$ ) was brain stem death a possible diagnosis. In 797 of these $(24 \% ; 22.9 \%$ to $25.9 \%$ ), however, tests for brain stem death were not carried out. Among the 2389 cases $(9.9 \% ; 9.5 \%$ to

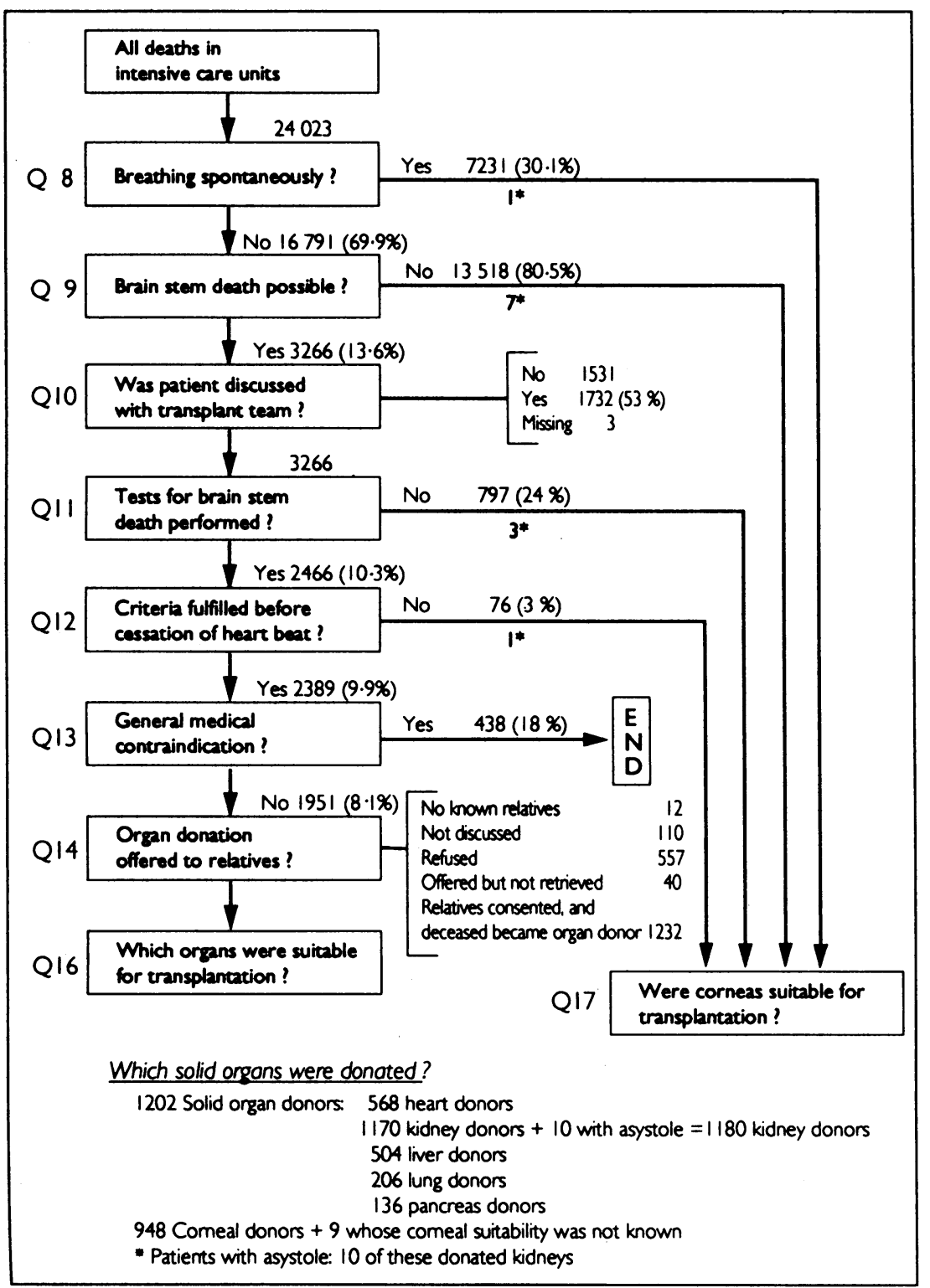

FIG 1-Audit flow chant for deaths in intensive care units in England (data for 1989 and 1990 combined)
$10 \cdot 3 \%$ ) in which brain stem death was confirmed there was a general medical contraindication to organ donation in $438(18 \% ; 16.8 \%$ to $19 \cdot 9 \%)$. Furthermore, of 1829 families of potential donors $(94 \%$; $93.3 \%$ to $95 \cdot 4 \%)$ who were asked about organ donation, $557(30 \% ; 28.3 \%$ to $32 \cdot 6 \%)$ refused.

In the second year of the audit (1990) there was a highly significant reduction in non-fulfilment of criteria for brain stem death before cessation of the heart beat (55 of 1310 cases $(4 \cdot 2 \%)$ in $1989 v 22$ of $1156(1 \cdot 9 \%)$ in $1990 ; \mathrm{p}<0.001)$.

\section{AUDITED DEATHS IN WELSH UNITS}

The mean age at death was higher in Wales $(62.4$ (SE 0.7 ) years) than in England, and in 581 cases $(85 \%)$ death was due to an extracranial cause. Only $45 \%$ of the audit forms from Wales were completed by doctors. There was no discussion of organ donation with five out of 54 families of potential donors; and of 49 families with whom organ donation was discussed, 18 (37\%; $95 \%$ confidence interval $23 \%$ to $50 \%$ ) refused to consent.

\section{POSSIBLE INCREASES IN ORGAN DONATION (ENGLAND)}

Table I (derived from the appendi ${ }^{3}$ ) summarises the suitability for transplantation of heart and other organs from brain stem dead potential donors and quantifies the possible increases in transplantable organs. Using data from the two years of audit in England, we estimate that in brain stem dead potential donors the heart is suitable for transplantation in $65 \%$ of cases, the kidneys in $95 \%$, the liver in $71 \%$, the lungs in $31 \%$, and the corneas in $92 \%$ (table I; appendix).

During 1989 and 1990, 568 heart donors were reported to the confidential audit. Table I, however, shows that an additional 672 suitable hearts might have been harvested had there been $(a)$ no refusal by relatives, $(b)$ no non-procurement, $(c)$ no restricted permissions, and $(d)$ no non-discussion. Table I confirms ${ }^{3}$ that for every organ considered, measures to improve rates of consent $(a+c+d)$ had greater potential than initiatives in procuring or allocating organs to increase the supply from brain stem dead potential donors. The main gain derived from measures to reduce the overall refusal rate.

The two years of confidential audit in England showed the following in respect of brain stem dead potential donors in intensive care:

No discussion of organ donation was the second most important reason (after relatives' refusal) for missed kidney donors, the loss being equivalent to $10 \%$ (112) of the 1170 brain stem dead patients in intensive care who donated kidneys ( $95 \%$ confidence interval $7 \cdot 9 \%$ to $11 \cdot 3 \%)$.

Non-procurement or difficulties in allocating organs was the second most notable cause of missed suitable liver and lung donors, the losses being 33\% (244; $95 \%$ confidence interval $29 \%$ to $36 \%$ ) of the offered total of 748 suitable liver donors and $35 \%(109 ; 29 \%$ to $40 \%)$ of the offered total of 315 suitable lung donors.

Corneal donation from brain stem dead potential donors might be improved nearly as much (possible increase of 494 suitable corneal donors over the two years) by specific measures to promote corneal donation when other organs are offered as by reducing the overall refusal rate (possible increase of 515 suitable corneal donors). The audit recorded 584 brain stem dead donors of corneas over the two years.

Restricted offers, non-procurement, and no discussion of donation accounted for nearly equal numbers (ratio $3: 3: 2$ ) of lost donations of hearts, the total lost (312) being equivalent to $55 \%$ of the 568 actual heart donations.

Restricted offers by otherwise consenting relatives accounted for losses equivalent to about a fifth of actual 


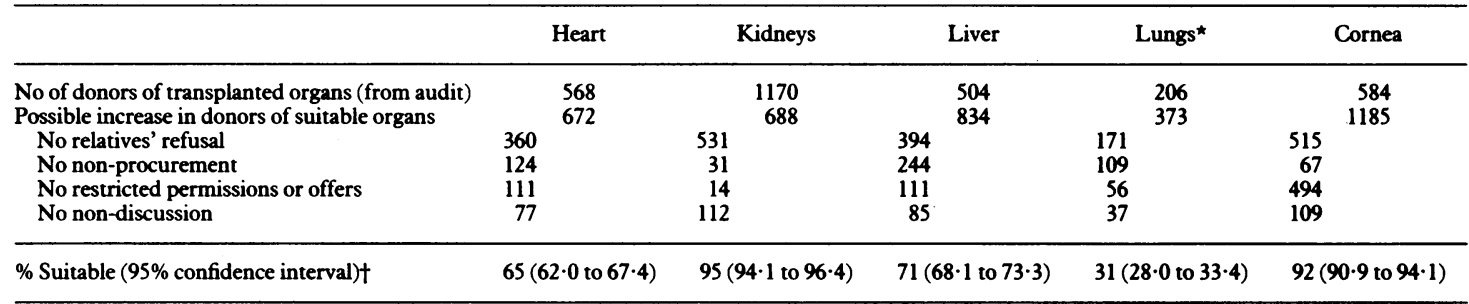

^Revised estimate taking account of deterioration in lungs by time of removal from donor. $\quad$ †See appendix.

heart, liver, and lung donations (111 hearts (20\% relative to the 568 donated), 111 livers ( $22 \%$ relative to the 504 donated), and 56 lung pairs ( $27 \%$ relative to the 206 donated)).

Achievement of transplantation (relative to kidneys and corrected for differential suitability) was $72 \%$ for hearts, $58 \%$ for livers, $55 \%$ for lungs, and $51 \%$ for corneas from brain stem dead potential donors in intensive care units and was consistent between audit years (data not shown).

Gentleman et al have asked about failure to use offered organs in the English audit. ${ }^{7}$ Based on the 1170 brain stem dead kidney donors in intensive care units in England during 1989 and 1990, we summarise as follows: $16 \%$ of suitable hearts that were offered were not actually donated (105 out of 658 offered; $95 \%$ confidence interval $13 \%$ to $19 \%$ ); $24 \%$ of suitable hearts or livers that were offered were not donated $(325$ out of $1371 ; 21 \%$ to $26 \%$ ); and $30 \%$ of suitable hearts or livers or lung pairs that were offered (without accounting for possible deterioration in lungs by the time of donor operation) were not donated (537 out of 1786; $28 \%$ to $32 \%$ ). Only $50 \%$ of kidney donors offered suitable corneas ( 587 out of $1170 ; 47 \%$ to $53 \%$ ), yet $92 \%$ of them should have had suitable corneas (see table I).

Reasons for failing to use other offered, suitable organs from kidney donors included non-suitability of

TABLE II-Audited solid organ donors and corneal donors from intensive care units in England by region in 1989 and 1990, and regional expectations per 100 deaths in intensive care units

\begin{tabular}{|c|c|c|c|c|c|c|c|}
\hline \multirow[b]{3}{*}{ Region } & \multicolumn{3}{|c|}{ Deaths in intensive care units } & \multicolumn{2}{|c|}{$\begin{array}{l}\text { Solid organ donors from } \\
\text { intensive care units in } \\
1989 \text { and } 1990\end{array}$} & \multicolumn{2}{|c|}{$\begin{array}{l}\text { Corneal donors from } \\
\text { intensive care units in } \\
1989 \text { and } 1990\end{array}$} \\
\hline & \multirow{2}{*}{ 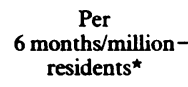 } & \multicolumn{2}{|c|}{ Validated forms } & \multirow{2}{*}{$\begin{array}{c}\text { Audited } \\
\text { donors }\end{array}$} & \multirow{2}{*}{$\begin{array}{c}\text { Expected } \\
\text { donors }\end{array}$} & \multirow{2}{*}{$\begin{array}{c}\text { Audited } \\
\text { donors }\end{array}$} & \multirow{2}{*}{$\begin{array}{c}\text { Expected } \\
\text { donors } \neq\end{array}$} \\
\hline & & 1989 & 1990 & & & & \\
\hline A & 146 & 848 & 800 & 119 & $82.5 \S$ & 77 & 65.0 \\
\hline B & 115 & 744 & 755 & 82 & 75.0 & 60 & $59 \cdot 1$ \\
\hline $\mathrm{C}$ & 120 & 1104 & 1093 & 117 & 109.9 & 83 & 86.7 \\
\hline D & 125 & 381 & 441 & 38 & $41 \cdot 0$ & 40 & $32 \cdot 4$ \\
\hline $\mathbf{E}$ & 147 & 892 & 890 & 51 & $89 \cdot 1 \|$ & 47 & $70 \cdot 3 \|$ \\
\hline $\mathbf{F}$ & 147 & 1159 & 964 & 86 & $106 \cdot 7 \|$ & 53 & 83.9 \\
\hline G & 219 & 1631 & 1457 & 119 & $154 \cdot 8 \|$ & 235 & $122 \cdot 0 \S$ \\
\hline $\mathbf{H}$ & 196 & 517 & 1034 & 58 & $76 \cdot 4 \|$ & 67 & $60 \cdot 7$ \\
\hline $\mathbf{J}$ & 111 & 509 & 532 & 98 & $52.0 \$$ & 34 & $41 \cdot 1$ \\
\hline $\mathbf{K}$ & 109 & 445 & 448 & 75 & $44 \cdot 7 \delta$ & 28 & $35 \cdot 3$ \\
\hline $\mathrm{L}$ & 137 & 706 & 772 & 81 & $73 \cdot 8^{\circ}$ & 53 & $58 \cdot 2$ \\
\hline$\vec{M}$ & 135 & 1359 & 1166 & 129 & $126 \cdot 7$ & 77 & $99.8 \|$ \\
\hline $\mathbf{N}$ & 115 & 519 & 574 & 37 & $54 \cdot 5 \|$ & 24 & $43 \cdot 1 \|$ \\
\hline $\mathbf{P}$ & 128 & 1030 & 780 & 106 & $91 \cdot 1$ & 57 & $71 \cdot 6$ \\
\hline $\mathbf{T}$ & $\mathrm{n} / \mathbf{a}$ & 289 & 184 & 6 & 23.9 & 13 & $18 \cdot 8$ \\
\hline Total & & 12133 & 11890 & 1202 & $\chi_{13}^{2}=133.9$ & 948 & $\chi_{13}^{2}=150 \cdot 2$ \\
\hline
\end{tabular}

$\mathbf{n} / \mathbf{a}=$ Not applicable

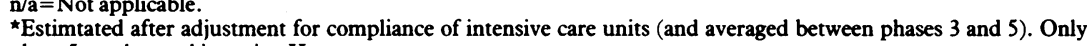
phase 5 results used in region $H$.

phase 5 results used in region $\mathrm{H}$.
$\dagger 5.23$ Solid organ donors expected per 100 analysed deaths in intensive care units in 1989 plus 4.78 solid organ †5.23 Solid organ donors expected per 100 analysed deaths in intensive care units in 1989 plus 4.78 solid organ
donors expected per 100 analysed deaths in intensive care units in 1990 . (Wales: Applying all England rate of 4.78 donors expected per 100 analysed deaths in intensive care units in 1990 . (Wales: Applying all England rate of 4.78
solid organ donors per 100 deaths in intensive care units in 1990 to 682 audited deaths in intensive care units in Wales in 1990 gives expectation of $32.6 v 29$ audited solid organ donors.)

\$4.04 Corneal donors expected per 100 analysed deaths in intensive care units in 1989 plus 3.85 corneal donors expected per 100 analysed deaths in intensive care units in 1990. (Wales: Applying all England rate of 3.85 corneal donors per 100 deaths in intensive care units in 1990 to 682 audited deaths in intensive care units in Wales in 1990 gives expectation of $26 \cdot 3 v 14$ audited corneal donors from intensive care units in Wales. Welsh intensive care units were therefore notably deficient in corneal donation compared with their English counterparts.)

§Region in which audited numbers of donors were 2 SD or more above expected per 100 deaths in intensive care units. URegion in which audited numbers of donors were 2 SD or more below expected per 100 deaths in intensive care
units.
TABLE III-Audited solid organ donors from intensive care units in England by region in 1989 and 1990, and regional expectations per 100 confirmed brain stem deaths in intensive care units

\begin{tabular}{|c|c|c|c|c|}
\hline \multirow[b]{2}{*}{ Region } & \multicolumn{2}{|c|}{$\begin{array}{l}\text { Confirmed brain stem deaths } \\
\text { in intensive care units }\end{array}$} & \multicolumn{2}{|c|}{$\begin{array}{l}\text { Solid organ donors from } \\
\text { intensive care units in } \\
1989 \text { and } 1990\end{array}$} \\
\hline & 1989 & 1990 & $\begin{array}{l}\text { Audited } \\
\text { donors }\end{array}$ & $\begin{array}{l}\text { Expected } \\
\text { donors }\end{array}$ \\
\hline A & 104 & 113 & 119 & $108 \cdot 7$ \\
\hline B & 79 & 61 & 82 & $70 \cdot 1$ \\
\hline C & 133 & 101 & 117 & $117 \cdot 2$ \\
\hline D & 41 & 51 & 38 & $46 \cdot 1$ \\
\hline $\mathbf{E}$ & 73 & 72 & 51 & $72 \cdot 6 \|$ \\
\hline $\mathbf{F}$ & 97 & 85 & 86 & $91 \cdot 2$ \\
\hline G & 109 & 120 & 119 & $114 \cdot 7$ \\
\hline H & 54 & 45 & 58 & $49 \cdot 6$ \\
\hline $\mathbf{J}$ & 73 & 66 & 98 & $69.9 \$$ \\
\hline$\hat{\mathbf{K}}$ & 70 & 57 & 75 & $63 \cdot 6^{\circ}$ \\
\hline L & 83 & 66 & 81 & $74 \cdot 6$ \\
\hline M & 155 & 144 & 129 & $149 \cdot 8$ \\
\hline $\mathbf{N}$ & 47 & 35 & 37 & $41 \cdot 1$ \\
\hline $\mathbf{P}$ & 115 & 105 & 106 & $110 \cdot 2$ \\
\hline $\mathbf{T}$ & 22 & 13 & 6 & $17 \cdot 5 \|$ \\
\hline Total & 1255 & 1134 & 1202 & $\chi_{13}^{2}=38.4$ \\
\hline
\end{tabular}

$\star 50 \cdot 1$ Solid organ donors expected per 100 confirmed brain stem deaths in intensive care units in 1989 plus same number expected in 1990. (Wales: Applying all England rate of 50.1 solid organ donors per 100 confirmed Applying all England rate of 50.1 solid organ donors per 100 confirmed brain stem deaths in intensive care units in 1990 to 71 confirmed brain stem
deaths in Welsh intensive care units in 1990 gives expectation of 35.6029 deaths in Welsh intensive care

audited solid organ donors.) SRegion in which audited numbers of donors were 2 SD or more beto
expected per 100 confirmed brain stem deaths in intensive care units. \#Region in which audited numbers of donors were 2 SD or more above expected per 100 confirmed brain stem deaths in intensive care units.

the offered organs by the time of donor operation, lack of suitable recipients, non-availability of a transplant team, lack of theatre time, shortage of intensive care facilities, and coroner's refusal. ${ }^{11}$ Coroner's refusal may prevent some, more usually all, organ donation by a potential donor. Of 112 "logistical" reasons which prevented some or all organ donation among 2005 potential donors in England and Wales, coroner's refusal predominated ( 36 cases; 1.8 per 100 potential donors).

\section{REGIONAL VARIATION IN DONOR RATES}

Table II shows the pronounced regional variation in deaths in intensive care units per million residents (based on small area statistics from the 1981 census, approximated after adjustment for compliance with the audit). Such regional variation makes it more appropriate to compare solid organ donor and corneal donor rates per 100 deaths in intensive care units rather than per million of the residents or total population.

Over the two years of confidential audit in England solid organ donor and corneal donor rates were 5.0 and 3.9 respectively per 100 deaths in intensive care units (table II: 1202 solid organ donors and 948 corneal donors among 24023 audited deaths), and the solid organ donor rate was 50 per 100 confirmed brain stem deaths (see table III: 1202 solid organ donors among 2389 confirmed brain stem deaths; $95 \%$ confidence interval 48 to 52 per 100). Table II gives the audited number of solid organ donors and of corneal donors in intensive care units by region; and for each region are shown the donors expected from applying the all 
England donor rates per 100 deaths in intensive care in 1989 and 1990. Table III gives the expected donors by region according to numbers of confirmed brain stem deaths.

\section{Solid organ donation}

During 1989 and 1990 the four Thames regions (E, F, G, and H) showed a deficit of audited solid organ donors from intensive care units compared with numbers expected per 100 deaths (table II). For three of these regions the explanation lay partly in the high proportion of deaths due to extracranial causes (fig 2) and was contributed to also by the older average age at death, particularly in regions $\mathrm{G}$ and $\mathrm{H}$. In region $\mathrm{E}$, which reported 51 solid organ donors during the two year audit period against 89.1 expected based on numbers of deaths and 72.6 expected based on numbers of confirmed brain stem deaths (table III), age and cause of death did not seem to be a sufficient explanation. Special health authority $\mathrm{T}$ also showed a deficit of audited solid organ donors on both counts.

Regions J and $\mathrm{K}$ (Wessex and Oxford) reported significantly more solid organ donors over the two year period than expected from the numbers of deaths. In both regions the proportion of deaths due to extracranial causes was low (fig 2). But Wessex also reported significantly more solid organ donors over the two years (98) than expected (69.9) from the number of confirmed brain stem deaths (table III). The consistent success in Wessex therefore had other explanations (see below).

Region A (Northern) reported 119 solid organ donors to the confidential audit against 82.5 expected during 1989 and 1990 from numbers of deaths and shared with Wessex and Oxford (fig 2) the characteristic of having a lower than average proportion of deaths due to extracranial causes (79\% in 1989 and 1990 compared with $81 \%$ and $83 \%$ in the two years for England as a whole). The 119 solid organ donors, however, accorded with the 108.7 expected from the number of confirmed brain stem deaths (table III).

Region N (Mersey) reported fewer solid organ donors (37) to the confidential audit than expected $(54.5)$ from the number of deaths, but the number was in line with that expected $(41 \cdot 1)$ from the number of confirmed brain stem deaths. High age standard

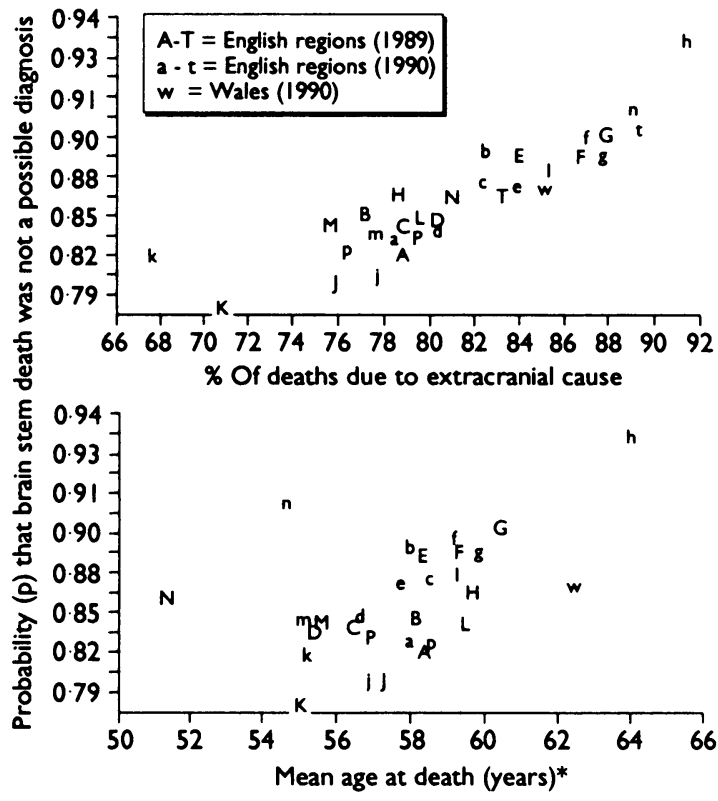

-Outliers were $T(34.5$ years; $p=0.90)$ and $t(23.4$ years; $p=0.87)$ FIG 2-Regional probabilities (p) that brain stem death was not possible diagnosis plotted against percentage of deaths due to extracranial causes and mean age at death. (Probability scale is unequally spaced but corresponds to equal graduations on scale of ln odds) deviations for regions $\mathrm{T}$ (29 years) and $\mathrm{N}$ (25 years) hinted at a possible explanation-namely, infant deaths (see below).

Applying the all England rates for 1990 of $4 \cdot 78$ solid organ donors and 3.85 corneal donors per 100 deaths in intensive care units to Wales gave expectations of 32.6 $v 29$ audited solid organ donors and $26.3 v 14$ audited corneal donors from intensive care units in Wales.

\section{Corneal donation}

With only two corneal donors per 100 deaths, Welsh intensive care units were notably deficient in corneal donation compared with their English counterparts (14 audited corneal donors $v 26.3$ expected; $\mathrm{p}<0.02$ ) Region G (South East Thames), expected to have 122 corneal donors over the two year period, reported nearly twice that number (235) to the audit, a rate of $7 \cdot 6$ corneal donors per 100 deaths (table II). Age is not a barrier to corneal donation, so the achievement in region $G$-through transplant coordinators focusing on corneal donation from intensive care units as well as the donation of solid organs-could be matched in other regions. Notably deficient in corneal donation from intensive care units were North Thames regions $\mathrm{E}$ and $\mathrm{F}$ and Mersey (region N). Midlands (region $\mathrm{M}$ ) also achieved a corneal donation rate of only three donors per 100 deaths in intensive care units.

\section{REGIONAL VARIATION IN BARRIERS TO DONATION}

There were six major barriers to solid organ donation from intensive care units in England-namely, $(a)$ brain stem death not a possible diagnosis, $(b)$ nonperformance of tests for brain stem death when brain stem death was a possible diagnosis, $(c)$ general medical contraindication to organ donation, (d) relatives' refusal, $(e)$ non-suitability of specific organs, and $(f)$ non-procurement of suitable offered organs (fig 1, table I). Detailed analysis of these barriers by using linear logistic regression to adjust for patient factors (notably age and cause of death) in the 1989 audit will be reported elsewhere. We concentrate on barriers $(a)$, $(d)$, and $(e)$ and give a simple summary, albeit substantiated by more formal analysis (data not shown).

Brain stem death not possible diagnosis-There was remarkable regional variation in whether brain stem death was a possible diagnosis both in $1989\left(\chi_{14}^{2}=84\right)$ and in $1990\left(\chi_{14}^{2}=115\right)$. This regional variation was highly confounded by the percentage of deaths due to extracranial causes (fig 2) and by mean age at death in intensive care. When these factors were taken into account regional variation was much reduced (in 1989 from $\chi_{14}^{2}=84$ to $\chi_{14}^{2}=36$ ). Figure 2 shows that there were some outliers and that regional changes occurred between 1989 and 1990. The most notable changes were in region $\mathrm{H}$, where audit compliance-poor in 1989 in some units - was improved in 1990 by transplant coordinators becoming involved in audit returns. The non-compliant units seem to have been those in which a high proportion of deaths were due to extracranial causes and age at death was greater. Region $\mathbf{N}$, as well as special health authority $\mathrm{T}$, was eccentric when mean age at death was plotted against brain stem death as a possible diagnosis. In region $\mathbf{N}$ (Mersey) there were $43(8 \%)$ infant deaths in the confidential audit in 1989 and $32(6 \%)$ in 1990 compared with 212 $(1.9 \%)$ per year in the rest of England (excluding Mersey and special health authority T; special health authority $\mathrm{T}$ reported $64(22 \%)$ and $70(38 \%)$ infant deaths in 1989 and 1990 respectively). The 3.5-fold excess of infant deaths in Mersey was highly significant statistically and goes some way to explaining its anomalous position in figure 2 (and with stronger reason for outlying special health authority $\mathrm{T}$ ).

General medical contraindication to organ donationTable IV shows that there was highly significant 
TABLE IV-Cross tabulation of regions by (a) whether for confirmed brain stem deaths there was a general medical contraindication to organ donation and (b) whether for brain stem dead potential donors relatives consented to organ donation. Data for 1989 and 1990 combined

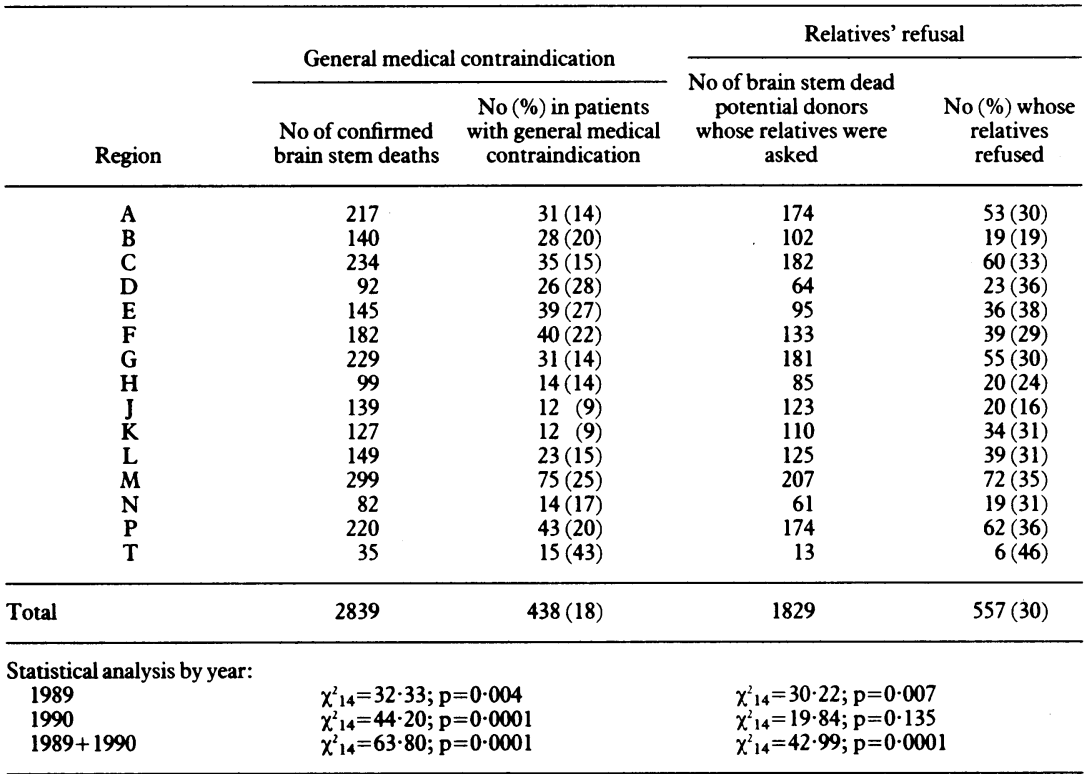

regional variation in the incidence of general medical contraindications to organ donation among patients in whom brain stem death was confirmed $\left(\chi_{14}^{2}=63 \cdot 80\right)$. Regional variation persisted even after adjustment for patient factors (regional variation after adjustment: $\left.1989, \chi_{14}^{2}=34 \cdot 1 ; 1990, \chi_{14}^{2}=35 \cdot 9\right)$. Region M (Midlands), special health authority $T$, and region $D$ (East Anglia) consistently reported high incidences of general medical contraindications; regions $\mathrm{J}$ and $\mathrm{K}$ (Wessex and Oxford) reported low rates. In region $G$ (South East Thames) the incidence of general medical contraindications in patients in whom brain stem death was confirmed nearly doubled in 1990 compared with 1989 (21 out of 120 compared with 10 out of 109 ).

Relatives' refusal-Table IV also compares relatives' refusal rates between regions in 1989 and 1990. Region $\mathrm{J}$ (Wessex) had a consistently low refusal rate by relatives (16\%) in 1989 and 1990.

\section{Discussion}

In England compliance with the confidential audit was $96 \%$ in the first year and $91 \%$ in the second. Moreover, the audit was estimated to be $84 \%$ representative of cadaveric solid organ donation. It was designed to report questions 1 to 14 (fig 1) with adequate precision after three months ${ }^{2}$; questions 14 to 18 after six months ${ }^{3}$; regional variation after one year; and, after two years, an assessment of regional consistency between 1989 and 1990 and updating with considerable precision of earlier estimates. These objectives were met through good cooperation from regional liaison officers and intensive care unit staff.

MYTHS

Brain stem death is a possible diagnosis in only $13.6 \%$ (between 1700 and 1800 cases) of the estimated 13000 patients each year who die in intensive care units in England and is confirmed in only $10 \%$ of these deaths (between 1200 and 1350 cases a year). These represent half and one third respectively ${ }^{2}$ of previous estimates and yield far fewer than the projected 1700 kidney donors needed a year in England. ${ }^{1}$ Moreover, the proportion of patients confirmed as brain stem dead who become actual donors $(50 \%)$ would need to increase substantially to meet even the present need for 1060 kidney donors a year in England.

Intervening between confirmed brain stem death and kidney donation are general medical contraindications to organ donation (in $18 \%$ of confirmed brain stem deaths, but subject to regional variation), failure to ask about organ donation (in only $6 \%$ of potential donor families, but the second reason (after relatives' refusal) for lost kidneys from brain stem dead potential donors), and relatives' refusal $(30 \%$ of families refused). As $94 \%$ of families of potential donors were asked about organ donation, required request legislation is unnecessary for the United Kingdom.

The large proportion of families who refuse consent suggests that we should reappraise opting out schemes, such as in Belgium, and Austria's presumed consent. Those two countries have the highest cadaveric kidney donor rates in Europe (in 1989 Austria had 26 kidney donors per million inhabitants and Belgium 20 per million). ${ }^{12}$ In Belgium, where $2 \%$ of the adult population has registered objection to organ donation, the philosophy is that opting out shares the onus of decision making between the deceased (in life) and surviving relatives. Does opting out, or presumed consent, lead to lower refusal rates by relatives? A confidential audit of deaths in intensive care units in Belgium and Austria would be revealing. How do Belgium and Austria compare with England in numbers of deaths in intensive care units per million population and in mean age at death and cause of death in these units, all of which are subject to regional variation in England? How do Belgian and Austrian intensive care facilities compare with those in England, where the average is $6 \cdot 1$ (SE $0 \cdot 18)$ beds, $5 \cdot 0(0 \cdot 17)$ funded beds, and $4 \cdot 4$ $(0 \cdot 15)$ staffed beds per unit?

\section{MORALS}

Because of the striking regional variation in estimated numbers of deaths in intensive care units per million residents we have introduced two new, apt measures for international comparison of solid organ donation from these units. These are $(a)$ solid organ donors (also corneal donors) per 100 deaths and (b) solid organ donors per 100 confirmed brain stem deaths. In 1989 and 1990 solid organ donor and corneal donor rates in England were $5 \cdot 0$ (95\% confidence interval $4 \cdot 7$ to $5 \cdot 3$ ) and $3.9(3.7$ to 4.2$)$ per 100 intensive care unit deaths and the solid organ donor rate 50 (48 to 52 ) per 100 confirmed brain stem deaths in these units. Regional variation in donation from intensive care units was dramatic when counted by all deaths in these units (table II; $\chi_{13}^{2}=134$ for solid organ donors and 150 for corneal donors in 1989 and 1990 combined) and remained highly significant $\left(p<0.001 ; \chi_{13}^{2}=38\right)$ when counted by confirmed brain stem deaths.

The Thames regions $(E, F, G$, and $H$ ), with a higher than average age at death in intensive care and higher proportions of deaths due to extracranial causes, were in deficit of solid organ donors per 100 intensive care unit deaths ( 314 audited $v 427$ expected), as were special health authority $T$ and Mersey region $(N)$, both of which reported high percentages of infant deaths to the confidential audit $(28 \%$ and $7 \% v 2 \%$ in the rest of England). Wessex and Oxford regions ( $J$ and $K$ ), with a younger than average age at death in intensive care and lower proportions of deaths due to extracranial causes, reported many more solid organ donors (173) than expected $(96.7)$ by numbers of deaths. The same was true of the Northern region (A) with its $79 \%$ of deaths due to extracranial causes and, in 1990, a low incidence of non-performance of tests for brain stem death when brain stem death was a possible diagnosis ( $12 \%$; 16 cases out of 132 possible brain stem deaths).

Whether brain stem death is a possible diagnosis and whether tests for brain stem death are performed differentiate between the above two measures of solid organ donation from intensive care units. Gentleman $e t$ 
al reported (a) that in 16 of 50 ventilated patients not tested for brain stem death asystole occurred before testing was done and $(b)$ that asystole may occur because of delay in initiating tests or because an interval of 12-24 hours is left between the first and second sets of tests.' The British criteria do not specify a long interval before repeating the tests, ${ }^{13}{ }^{14}$ and delay increases the likelihood of hypotension. In future audits reasons for non-performance of tests for brain stem death should be sought. The Glasgow data suggest that non-performance of tests for brain stem death could be reduced by up to one third without delays. The Northern region halved its incidence of non-performance of tests for brain stem death between 1989 and 1990, and the incidence of non-performance in the North East Thames region has been consistently lower by a quarter, at $18 \%$, than for England as a whole.

Regional variation in whether brain stem death was a possible diagnosis was related to the percentage of deaths due to extracranial causes, mean age at death in intensive care units, and the percentage of infant deaths included in the confidential audit. The second measure of how regions rank for solid organ donation therefore sets aside these variations and concentrates only on the proportion of confirmed brain stem dead patients who become solid organ donors. There remained a highly significant regional variation $\left(p<0.001 ; \chi_{13}^{2}=38\right)$. Pre-eminent was Wessex (region $\mathrm{J})$ with a rate of solid organ donation among confirmed brain stem dead patients of $71 \%$ (98 solid organ donors from 139 confirmed brain stem deaths). The low refusal rate by relatives in Wessex $(16 \%)$ was attributed to good local communication between transplant and intensive care unit professionals and with the public; assiduous coordination; and a generous public. By contrast, North West Thames (region E) had only 51 audited solid organ donors (35\%) from 145 confirmed brain stem deaths and special health authority $\mathrm{T}$ six solid organ donors from 35 confirmed brain stem deaths.

\section{MEMORANDA}

Among potential transplant donors - that is, patients confirmed as brain stem dead and with no general medical contraindication to organ donation-the suitability of specific organs is estimated as follows: the heart is suitable in $65 \%$ of cases, the kidneys in $95 \%$, the liver in $71 \%$, the lungs in $31 \%$, and the corneas in $92 \%$. When comparing donation rates there is a need to correct for these different suitabilities: relative to kidney donation, achievement is $72 \%$ for hearts, $58 \%$ for livers, $55 \%$ for lungs, and $51 \%$ for corneas from brain stem dead potential donors. The reasons for shortfall in achievement are different for the different organs. Difficulties in procuring or allocating organs are the most notable cause (after the overall refusal rate) of missed suitable liver and reportedly suitable lung donors. Non-procurement, restricted offers, and no discussion accounted for nearly equal numbers of lost heart donations (in the ratio 3:3:2). Corneal achievement could be improved by specific measures to promote corneal donation when other organs are offered. Restricted offers by otherwise consenting relatives accounted for losses equivalent to roughly a fifth of actual heart, liver, and lung donations. Corneas apart, restricted permission affected solid organs similarly, with no particular emotional or other reservation against heart donation. Does failure to discuss the donation of extrarenal organs masquerade as restricted permission?

In summary, we consider how kidney donation from intensive care units would be affected by just two changes-namely, (a) a quarter reduction in non- performance of tests for brain stem death if delays were minimised, and $(b)$ a quarter reduction in relatives' refusals, as occurred in October and November 1989 during sustained publicity about the need for transplantation. Instead of 1768 possible and 1300 confirmed brain stem deaths in intensive care units there would be 100 additional confirmed brain stem deaths. Instead of 696 offered donors from 1300 confirmed brain stem deaths there would be an additional 72 offered donors if refusals were reduced by a quarter. From the 100 additional confirmed brain stem deaths there would be an additional 54 offered donors-or 59 if the consent rate increased from $70 \%$ to $77 \cdot 5 \%$. Hence these two changes could increase the number of cadaveric kidney donors by nearly a fifth. Action on general medical contraindications to organ donation could diminish another major barrier: specialist review of over 400 listed general medical contraindications in the confidential audit will be reported subsequently.

England's goal should be a realistic $20 \%$ increase in the number of cadaveric kidney donors from intensive care units by concentration on performance of tests for brain stem death without undue delay, discussion with transplant teams about organ suitability, and increased consent rates (including discussion of extrarenal organs). Attention to logistics and organ allocation may also reduce non-procurement of offered suitable organs.

Confidential audit of all deaths in intensive care was supported by a grant from the Department of Health. We thank particularly the doctors, nurses, coordinators, and others in intensive care units who completed audit forms but whose identity is unknown to us for reasons of confidentiality. We thank the United Kingdom Transplant Service for information on numbers of cadaveric donors. We are indebted to our regional liaison officers for the contacts which they have maintained with intensive care units: Dr Julie Bagnall, Sister Deirdre Barr, Mrs Fiona Carter, Mr A J Cassidy, Mr J Chapman, Mr John S Chapman, Mr R Collins, Ms Alison Crombie, Mr D Grift, Ms Carol Hall, Ms Nilli Lamakan, Mrs Christine Lyon, Miss F Martin, Ms Elaine Matthewman, Ms Joanna Nicholls, Mr M O'Donnell, Dr M R Owen, Miss Caroline Phelps, Dr M A Pitman, Dr John Raison, Dr D Richardson, Dr M Rivlin, Dr T Sussman, Mr Frank Stockwell, Mr Alan Waller, Ms Carol Wicks, Miss Jenny Wright. Mr Myc Riggulsford, former public relations officer at the UK Transplant Service, gave constructive advice on audit form content. Also consulted were: British Transplantation Society, British Organ Donor Society, Faculty of Anaesthetists, Intensive Care Society, Joint Consultants Committee, regional and district general managers, Royal College of Physicians, Society of British Neurological Surgeons, the then UK Transplant Service management committee. London: HMSO, 1987. (Chairman Sir Raymond Hoffenberg.)

2 Gore SM, Hinds CJ, Rutherford AJ. Organ donation from intensive care units in England. BMF 1989;299:1193-7.

3 Gore SM, Taylor RMR, Wallwork J. Availability of transplantable organs from brain stem dead donors in intensive care units. $B M \mathcal{F} 1991 ; 302: 149-53$. 4 Cohen AT. Organs for transplantation. BMF 1989;299:1463.

5 Collins C. Organs for transplantation. BMF 1989;299:1463.

6 Feest TG, Riad HN, Collins CH, Golby MGS, Nicholls AJ, Hamad SN. Protocol for increasing organ donation after cerebrovascular deaths in a district general hospital. Lancet 1990;335:1133-5.

7 Gentleman D, Easton J, Jennett B. Brain death and organ donation in neurosurgical unit: audit of recent practice. BMF 1990;301:1203-6.

8 Salih MAM, Harvey I, Frankel S, Coupe DJ, Webb M, Cripps HA. Potential availability of cadaver organs for transplantation. $B M \mathcal{Y}$ 1991;302: 1053-5.

9 Payne JN, Bowns IR, Lyon C. Organs for transplantation. BMf 1989;299: 1463

10 Wallwork J. Organs for transplantation. Improvements needed in supply and use. $B M \mathcal{f} 1989 ; 299: 1291-2$.

11 Gore SM. Organ donation in a neurosurgical unit. BMF 1991;302:52.

12 Eurotransplant Foundation. Annual report 1989. Leiden: Eurotransplant, 1989:21.

13 Conference of Medical Royal Colleges and their Faculties in UK. Diagnosis of brain death. $B M \mathcal{F}$ 1976;ii:1187-8.

14 Conference of Medical Royal Colleges and their Faculties in UK. Diagnosis of death. BMF 1979;i:332.

(Accepted 13 November 1991) 
Suitability of organs for transplantation from brain stem dead potential donors as reported by intensive care units in England. Figures are numbers of donors. Data for 1989 and 1990 combined

\begin{tabular}{|c|c|c|c|c|c|c|}
\hline & \multicolumn{3}{|c|}{ Suitable } & \multirow[b]{2}{*}{ Unsuitable } & \multirow[b]{2}{*}{ Other } & \multirow[b]{2}{*}{ Total } \\
\hline & Donated & $\begin{array}{c}\text { Not } \\
\text { procured }\end{array}$ & $\begin{array}{c}\text { Not } \\
\text { offered }\end{array}$ & & & \\
\hline \multicolumn{7}{|c|}{ Corneal pair } \\
\hline No known relatives or transplantation not discussed & 4 & & & 13 & & 122 \\
\hline Refusal by relatives & & & 399 & 26 & 132 & 557 \\
\hline Consent & 580 & 67 & 339 & 80 & $206\left(168^{\star}\right)$ & 1272 \\
\hline Total & 584 & 67 & 794 & 119 & 387 & 1951 \\
\hline \multicolumn{7}{|c|}{ Heart } \\
\hline No known relatives or transplantation not discussed & 2 & & 44 & 44 & 32 & 122 \\
\hline Refusal by relatives & & & 375 & 103 & 79 & 557 \\
\hline Consent & 566 & 124 & 75 & 417 & $90\left(55^{\star}\right)$ & 1272 \\
\hline Total & 568 & 124 & 494 & 564 & 201 & 1951 \\
\hline \multicolumn{7}{|c|}{ Kidney pair } \\
\hline No known relatives or transplantation not discussed & 4 & & 55 & 33 & 30 & 122 \\
\hline Refusal by relatives & & & 458 & 31 & 68 & 557 \\
\hline Consent & 1166 & 31 & 7 & 60 & $8\left(7^{\star}\right)$ & 1272 \\
\hline Total & 1170 & 31 & 520 & 124 & 106 & 1951 \\
\hline \multicolumn{7}{|c|}{ Liver } \\
\hline $\begin{array}{l}\text { No known relatives or transplantation not discussed } \\
\text { Refusal by relatives }\end{array}$ & 1 & & $\begin{array}{r}48 \\
391\end{array}$ & $\begin{array}{l}38 \\
69\end{array}$ & $\begin{array}{l}35 \\
97\end{array}$ & $\begin{array}{l}122 \\
557\end{array}$ \\
\hline Consent & 503 & 244 & 66 & 337 & $122\left(64^{\star}\right)$ & 1272 \\
\hline Total & 504 & 244 & 505 & 444 & 254 & 1951 \\
\hline \multicolumn{7}{|c|}{ Lung pairt } \\
\hline $\begin{array}{l}\text { No known relatives or transplantation not discussed } \\
\text { Refusal by relatives }\end{array}$ & & 1 & $\begin{array}{r}40 \\
329\end{array}$ & $\begin{array}{r}47 \\
136\end{array}$ & $\begin{array}{l}34 \\
92\end{array}$ & $\begin{array}{l}122 \\
557\end{array}$ \\
\hline Consent & $\begin{array}{c}206 \\
{[206]}\end{array}$ & $\begin{array}{c}228 \\
{[109]}\end{array}$ & {$[31 \cdot 6]$} & $\begin{array}{l}628 \\
{[781 \cdot 4]}\end{array}$ & $144\left(80^{\star}\right)$ & 1272 \\
\hline Total & $\begin{array}{c}206 \\
{[206]}\end{array}$ & $\begin{array}{c}229 \\
{[110]}\end{array}$ & $\begin{array}{l}435 \\
{[400 \cdot 6]}\end{array}$ & $\begin{array}{l}811 \\
{[964 \cdot 4]}\end{array}$ & 270 & 1951 \\
\hline
\end{tabular}

$\star$ Includes suitability of stated organ or organ pair not known or donation not known, or both. Figures in parentheses are numbers for whom there was no offer.

†In 1989 of 143 patients with lungs suitable for transplantation but not procured, 83 donated heart; in 1990 of 86 patients with lungs suitable but not procured, 36 donated heart. For analysis lungs were regarded as unsuitable in these 119 patients; adjusted totals are given in square brackets.

Given relatives' consent, suitability of organs or organ pairs for transplantation was determined as follows:

Corneal pairs $-\%$ Suitable $=(986 /(986+80)) \times 100=92 \cdot 5(95 \%$ confidence interval $90 \cdot 9$ to $94 \cdot 1)$.

Hearts $-\%$ Suitable $=(765 /(765+417)) \times 100=64 \cdot 7(95 \%$ confidence interval $62 \cdot 0$ to $67 \cdot 4)$

Kidney pairs $-\%$ Suitable $=(1204 /(1204+60)) \times 100=95 \cdot 3 \%(95 \%$ confidence interval $94 \cdot 1$ to $96 \cdot 4)$.

Livers $\quad-\%$ Suitable $=(813 /(813+337)) \times 100=70 \cdot 7(95 \%$ confidence interval $68 \cdot 1$ to $73 \cdot 3)$

Lung pairs $\quad-\%$ Suitable $=(346 \cdot 6 /(346 \cdot 6+781 \cdot 4)) \times 100=30 \cdot 7(95 \%$ confidence interval $28 \cdot 0$ to $33 \cdot 4)$.

\section{ONE HUNDRED YEARS AGO}

\section{COMPARATIVE PATHOLOGY OF THE WHITE MAN AND THE NEGRO}

From an analysis of the cases of 430,466 negro patients treated by the medical department of the American Bureau of Refugees, from 1865 to 1872 , Dr. Reyburn, late Surgeon United States Volunteers, draws certain conclusions as to the proclivity of the African race to particular types of disease. A basis of comparison between the pathological tendencies of white people and negroes respectively is afforded by 22,053 cases of disease in white patients treated during the same period. Among the negroes there were 152,141 cases of remittent and intermittent fever, and Dr. Reyburn thinks there is no difference as regards susceptibility to these fevers between the white and the coloured populations of the Southern States. The statistics further show that the statements commonly made concerning the extreme liability of negroes to scrofulous disease and pulmonary tuberculosis rest on no solid foundation. The deaths from typhoid fever among the negroes amounted to about 25 per cent. of the cases treated, this high mortality being dependent on the frequency of severe intestinal lesions. The death-rate from diarrhœa and dysentery was also high, owing, according to Dr. Reyburn, to the ignorance of hygienic laws which prevails among the coloured people. The negro freedman and the white refugee alike fell victims to epidemic cholera, one half of the patients dying under every variety of treatment. Delirium tremens was of very rare occurrence among the negroes-a circumstance which Dr. Reyburn attributes to "the want of development of the cerebral hemispheres." Alcoholism, he says, is in the negro more apt to lead to epileptiform convulsions or mania than to delirium tremens. Dr. Reyburn concludes that the negro has not the same power of resistance to acute inflammations, such as pneumonia, as the Caucasian, and does not recover from protracted and exhausting illness, such as typhoid fever, so well as the latter. On the other hand the negro has greater reparative power after injuries and surgical operations than the white man, in this resembling the other dark races in Asia and elsewhere. (BMF 1892;i:296) 